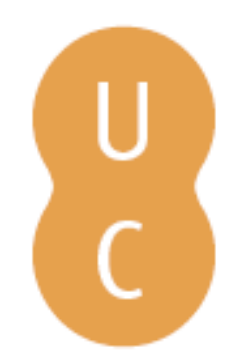

\title{
nommalina
}

\section{Utilização de cromatografia supercrítica na purificação de compostos bioactivos}

Autor(es): $\quad$ Rosa, Paulo de Tarso Vieira e

Publicado por: Imprensa da Universidade de Coimbra

URL

persistente:

URI:http://hdl.handle.net/10316.2/36926

DOI:

DOI:http://dx.doi.org/10.14195/978-989-26-0881-5_15

Accessed : $\quad$ 26-Apr-2023 16:16:32

A navegação consulta e descarregamento dos títulos inseridos nas Bibliotecas Digitais UC Digitalis, UC Pombalina e UC Impactum, pressupõem a aceitação plena e sem reservas dos Termos e Condições de Uso destas Bibliotecas Digitais, disponíveis em https://digitalis.uc.pt/pt-pt/termos.

Conforme exposto nos referidos Termos e Condições de Uso, o descarregamento de títulos de acesso restrito requer uma licença válida de autorização devendo o utilizador aceder ao(s) documento(s) a partir de um endereço de IP da instituição detentora da supramencionada licença.

Ao utilizador é apenas permitido o descarregamento para uso pessoal, pelo que o emprego do(s) título(s) descarregado(s) para outro fim, designadamente comercial, carece de autorização do respetivo autor ou editor da obra.

Na medida em que todas as obras da UC Digitalis se encontram protegidas pelo Código do Direito de Autor e Direitos Conexos e demais legislação aplicável, toda a cópia, parcial ou total, deste documento, nos casos em que é legalmente admitida, deverá conter ou fazer-se acompanhar por este aviso. 
IOMATERIAIS APLICADOS AO DESENVOLVIMENTO DE SISTEMAS TERAPÊUTICOS AVANÇADOS

IOMATERIALES APLICADOS AL DISEÑO DE SISTEMAS TERAPÉUTICOS AVANZADOS

Hermínio C. de Sousa Mara E. M. Braga Alejandro Sosnik (editores) 


\section{CAPÍTULO 15. UTILIZAÇÃO DE CROMATOGRAFIA SUPERCRÍTICA NA PURIFICAÇÃO DE COMPOSTOS B I O A T I V O S}

Paulo de Tarso Vieira e Rosa Departamento de Físico-Química, Instituto de Química, Universidade Estadual de Campinas (UNICAMP). Rua Josué de Castro S/N, 13083-970, Campinas, Brasil.

\section{Resumo:}

A cromatografia supercrítica foi introduzida em 1962 com a promessa de que iria substituir tanto a cromatografia gasosa quanto a líquida. Passados cerca de 50 anos, pode-se observar que este processo de separação ainda procura um local de destaque, sendo empregado somente em algumas análises específicas. Razões como a pouca robustez dos sistemas experimentais inicialmente disponíveis, os quais foram adaptados das cromatografias convencionais, e o pouco entendimento do comportamento do fluido supercrítico podem ser causas para esta lenta disseminação da técnica. Sistemas comerciais desenvolvidos especificamente para esta modalidade de cromatografia tem favorecido o aumento da utilização da técnica com a possibilidade do uso das vantagens específicas dos fluidos supercríticos como a baixa viscosidade e o alto coeficiente de difusão, se comparado com o fluido líquido, levando a separações mais rápidas e com grande eficiência e pela possibilidade de redução do consumo de solventes orgânicos, trazendo ganhos ambientais para os processos. Neste capítulo é apresentada uma revisão das principais características e desenvolvimentos da cromatografia supercrítica 
utilizadas como ferramenta analítica e na purificação de compostos tanto nas escalas semi-preparativa como preparativa. Além disto, as principais fases estacionárias, métodos de detecção do material separado e parâmetros relevantes para a otimização dos processos de separação são discutidos.

Palavras-chave: cromatografia supercrítica, dióxido de carbono supercrítico, cromatografia analítica, cromatografia semi-preparativa, cromatografia preparativa.

\section{Abstract:}

Supercritical chromatography was originally introduced in 1962 aiming to substitute both the gas and the liquid chromatography. After almost 50 years, this separation technique is still trying to find its place in the marked, been used only in some special cases. The main reasons for that can be the lack of robustness of the developed equipment, in general adapted from the conventional chromatographies, and the poor comprehension of the supercritical fluids by the users of the technique. The new commercial systems developed exclusively for supercritical chromatography are increasing the use of this separation method and are allowing to exploit the advantages of the supercritical fluids such as low viscosity and high diffusion coefficient, leading to faster and more efficient separations, and also permitting lower quantity organic solvent necessary in the process, resulting in some interesting environmental advantages. In this chapter, the main characteristics and advances of the supercritical chromatography used in the analytical, semi-preparative, and preparative scales are reviewed. Furthermore, the more relevant stationary phases, detection methods, and parameters used in the process optimization are discussed.

Keywords: supercritical chromatography, supercritical carbon dioxide, analytical chromatography, semi-preparative chromatography, preparative chromatography. 


\subsection{Introdução}

Cromatografia é um processo físico-químico de separação baseado nas diferentes intensidades de interações que solutos presentes em uma fase móvel tem com uma fase estacionária localizada em uma coluna. As duas principais categorias de cromatografia são classificadas de acordo com o estado físico da fase móvel sendo estas a gasosa (GC) e a líquida (LC). A cromatografia gasosa apresenta altas eficiências de separação devido às características de transferência de massa dos gases e podem utilizar detectores universais como os condutométricos e os de ionização de chama. Como desvantagem são restritas para a identificação de compostos voláteis e que sejam termicamente estáveis. Já a cromatografia líquida pode ser utilizada para compostos não voláteis e termicamente instáveis, porém com baixa eficiência de separação devido às limitações de transferência de massa características dos líquidos.

Quando um fluido supercrítico é utilizado como fase móvel em um processo de separação cromatográfico este é denominado de cromatografia supercrítica (SFC). Um fluido é considerado como supercrítico quando tanto a temperatura quanto a pressão do sistema estiverem acima das condições do seu ponto crítico. Os fluidos nestas condições apresentam propriedades físico-químicas intermediárias entre as apresentadas em seu estado líquido e gasoso. Em geral, as densidades são elevadas devido à altas pressões, o que resulta em grandes poderes de solvatação se comparados com o mesmo fluido no estado gasoso, e baixas viscosidades e altos coeficientes de difusão se comparados com o fluido no estado líquido. Os valores característicos às duas últimas propriedades físico-químicas favorecem os sistemas que utilizam fluidos supercríticos a terem altas taxas de transferência de massa, se comparados com sistemas em fase líquida.

Historicamente, a cromatografia supercrítica teve início em 1962 com a separação de derivados de porfirina termolábeis utilizando misturas de clorofluorometanos supercríticos como fase móvel [1]. A motivação deste experimento foi a baixa pressão de vapor das porfirinas o que levava a decomposição das mesmas quando analisadas por cromatografia gasosa. A coluna tinha $75 \mathrm{~cm}$ de comprimento e era preenchida com polietileno 
glicol sobre polímero poliaromático reticulado (Chromosorb W). Após sua introdução, a cromatografia supercrítica seguiu a tendência da cromatografia gasosa de utilizar colunas capilares abertas e recobertas com filmes de materiais adsorventes depositados. Nestas aplicações, as colunas capilares empregadas apresentavam diâmetros internos menores que as usualmente utilizadas na cromatografia gasosa e os filmes de fase estacionária tiveram que começar a serem reticulados para diminuir a tendência de serem removidos da coluna pela fase móvel supercrítica. A cromatografia supercrítica utilizada como uma extensão da cromatografia gasosa apresentou diversos problemas operacionais tais como a aplicação para compostos praticamente apolares, baixo poder de solvatação do $\mathrm{CO}_{2}$ puro, pouca robustez da injeção das amostras, tempos longos de separação devido a menor eficiência do sistema se comparado com a cromatografia gasosa, entupimentos da coluna e a quebra de partes do sistema devido a altas pressões [2]. Devido a estas dificuldades, no final dos anos 80 foram realizados estudos mais sistemáticos de utilização de cromatografia supercrítica em colunas empacotadas, onde os melhores resultados foram obtidos. Hoje, praticamente todos os sistemas de cromatografia supercrítica são extensões da cromatografia líquida de alta eficiência (HPLC).

Taylor em 2009 [3] apresentou uma classificação de diversos métodos cromatográficos dependente das condições de temperatura e pressão utilizadas na separação dos solutos. Assim, de fases móveis menos densas para mais densas temos a cromatografia gasosa, a cromatografia gasosa a altas pressões, cromatografia gasosa de solvatação, cromatografia com fluido supercrítico, cromatografia com fluido subcrítico, cromatografia com fluidez aumentada, cromatografia líquida a altas temperaturas e, finalmente, cromatografia líquida. Estas diversas modalidades de cromatografias permitem que estes métodos de separações sejam utilizados na identificação e purificação de uma ampla gama de compostos. Quando colunas abertas ou empacotadas utilizando dióxido de carbono supercrítico como fase móvel são empregadas, podemos ter qualquer uma das modalidades acima citadas em um único equipamento [4]. Como seria possível realizar todos os tipos de separações em um único equipamento, iniciou-se uma série de tentativas para tentar unificar os métodos 
cromatográficos [5]. Apesar destes esforços, devido às diversas restrições mecânicas e econômicas ainda não foi possível chegar a esta unificação.

Dependendo da escala e objetivo dos métodos cromatográficos empregados, seguindo a classificação proposta por Berger [6], eles podem ser classificados como cromatografia analítica, cromatografia semi-preparativa e cromatografia preparativa. Neste capítulo, serão apresentadas as principais características da cromatografia supercrítica bem como algumas aplicações desta tanto para a identificação quanto para a purificação de compostos bioativos. Em geral, a cromatografia que empregue o dióxido de carbono na fase móvel em condições de temperatura e pressão acima de seu ponto crítico $(304,25 \mathrm{~K} \mathrm{e} \mathrm{7,38} \mathrm{MPa)} \mathrm{são} \mathrm{apresentadas} \mathrm{na} \mathrm{literatura}$ como cromatografia supercrítica. Como é possível utilizar quantidades pequenas ou moderadas de solventes orgânicos para modificar as características de polaridade do dióxido de carbono, nem sempre as condições empregadas na separação estão acima do ponto crítico da mistura. Mesmo assim, neste texto, estes sistemas serão considerados como de cromatografia supercrítica.

\subsection{Cromatografia analítica}

Da mesma forma que na cromatografia líquida ou gasosa, a separação dos solutos presentes na fase móvel sub ou supercrítica se dá por suas diferentes interações com a fase estacionária presente em uma coluna. Quanto maior for a interação de um soluto, maior será o seu tempo necessário para eluir da coluna e assim ocorre a separação. A intensidade da interação que levará à separação é dada pela correta seleção das fases estacionária e móvel, bem como das condições operacionais utilizadas. O objetivo da cromatografia analítica é separar da melhor maneira possível os solutos de interesse de forma que quando saem da coluna cromatográfica possam ser detectados como bandas únicas e assim, possam ser identificados e/ou quantificados. Para tal, pequenas quantidades de amostras são introduzidas na coluna, com a finalidade de estreitar e manter uma forma mais simétrica os picos de cada soluto. 
Colunas cromatográficas com diâmetros inferiores a $10 \mathrm{~mm}$ e a utilização de vazões da fase móvel de 0,1 a $10 \mathrm{~mL} / \mathrm{min}$ podem ser frequentemente encontradas na cromatografia supercrítica analítica.

Dentre as três modalidades de utilização da cromatografia, a analítica é a mais empregada, presente em diversos laboratórios. A Figura 15.1 apresenta uma representação esquemática de unidade de cromatografia supercrítica analítica.

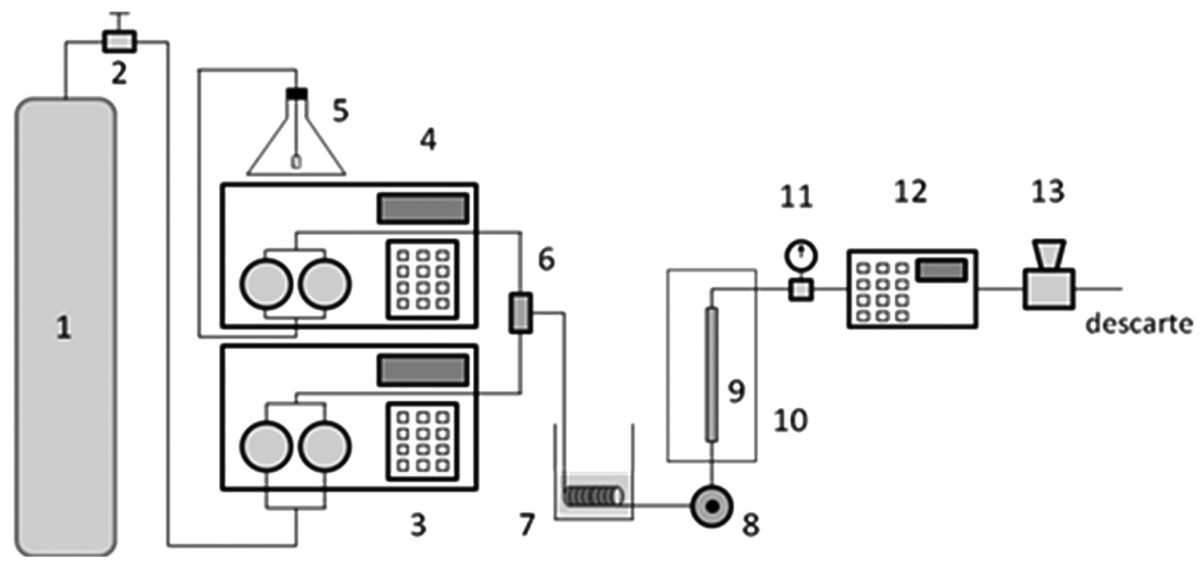

Figura 15.1. Representação esquemática de um cromatógrafo supercrítico analítico. (1) representa o reservatório de $\mathrm{CO}_{2}$, (2) uma válvula de bloqueio do dióxido de carbono, (3) a bomba de $\mathrm{CO}_{2}$, (4) a bomba de cossolvente, (5) o reservatório de cossolvente, (6) um misturador, (7) um pré-aquecedor, (8) a válvula de injeção, (9) a coluna cromatográfica, (10) um forno, (11) um manômetro ou transdutor de pressão, (12) um detector e (13) uma válvula controladora de pressão.

Como pode ser observado na Figura 15.1, os sistemas de cromatografia líquida e supercrítica são bem parecidos, mas algumas particularidades da cromatografia supercrítica devem ser ressaltadas. A bomba de $\mathrm{CO}_{2}$ deve ser refrigerada para garantir que este esteja no estado líquido durante o bombeamento, permitindo assim que a vazão seja mantida em um valor constante durante a separação. Como a eficiência da bomba pode variar com as temperaturas ambiente e do $\mathrm{CO}_{2}$, em alguns sistemas as bombas são controladas utilizando os dados de vazão mássica do fluido em sua entrada, geralmente medidos utilizando um medidor 
de vazão mássica do tipo coriolis, para garantir uma boa estabilidade da vazão no sistema. Outra alternativa é a utilização de bombas seringas refrigeradas de alta pressão para o escoamento do fluido supercrítico. Estas bombas são capazes de fornecer vazões constantes de $\mathrm{CO}_{2}$ em uma ampla faixa de vazões, apesar do custo consideravelmente mais elevado. As bombas de cossolventes podem ser as tradicionalmente utilizadas em cromatografia líquida. As válvulas de injeção do tipo Rheodyne, similares às empregadas em HPLC, são empregadas na cromatografia supercrítica. A pressão do sistema durante a separação é mantida constante com o auxílio de válvulas controladoras de pressão (as mais utilizadas são do tipo BPR - back pressure regulator). Desta forma, os detectores operam sob alta pressão e devem ser robustos para suportarem as condições de pressão empregadas durante o processo de separação. As principais fases estacionárias e os principais detectores utilizados na cromatografia supercrítica são apresentados a seguir.

\subsubsection{Fases Estacionárias}

As fases estacionárias utilizadas para a cromatografia supercrítica seguem os mesmos tipos utilizadas na cromatografia líquida. Diversas forças intermoleculares ou até mesmo reações químicas superficiais podem ocorrer entre os solutos e grupos de reconhecimento presentes na fase estacionária. Os principais tipos de adsorção envolvidos podem ser classificados como físicas ou químicas. Nas adsorções físicas, interações não-covalentes tais como forças de van der waals, interações eletrostáticas, interações hidrofóbicas e ligações de hidrogênio podem ocorrer de forma isolada ou em conjunto e levar ao retardo dos compostos que tiverem interações mais intensas com a fase estacionária, realizando assim a separação entre os solutos. No caso da adsorção química, interações covalentes são formadas entre o soluto e a fase estacionária, sendo geralmente necessária a mudança das propriedades físico-químicas da fase móvel para que ocorra a dessorção do soluto adsorvido. Assim, fases estacionárias 
normais, reversas, e de resolução quiral podem ser empregadas para na separação de diversas classes de solutos por cromatografia supercrítica. Apesar das fases estacionarias estarem apresentadas na seção de cromatografia em escala analítica, as mesmas são também utilizadas em escala semi-preparativa e preparativa.

\subsubsection{Fases estacionárias normais}

O termo fase estacionária normal representa que a polaridade desta fase é maior do que a da fase móvel. Assim, materiais adsorventes hidrofílicos como sílicas, alumina, óxido de magnésio, entre outros podem ser empregados. Com o avanço da utilização das técnicas de cromatografia líquida de alta eficiência, a fase estacionária normal perdeu sua importância sendo praticamente trocada pela cromatografia em fase reversa [6]. A cromatografia supercrítica marca o retorno das fases normais, uma vez que o dióxido de carbono é uma molécula apolar com grande momento quadrupolar. Desta forma ela é capaz de solubilizar compostos hidrofóbicos e com polaridades intermediárias que podem ter nitrogênio, flúor, cloro, enxofre ou oxigênio em suas estruturas. Estes heteroátomos podem interagir com a fase estacionária normal através de interações do tipo dipolo-dipolo e/ou com ligações de hidrogênio. Como uma consequência destas interações, os compostos que apresentem átomos mais eletronegativos serão mais retardados na coluna cromatográfica e, então, podem ser separados. Neste tipo de separação, o dióxido de carbono supercrítico puro pode ser utilizado como fase móvel, desde que os solutos de interesse sejam solúveis neste solvente. Devido a possíveis grandes interações entre os solutos e a fase estacionária, ou quando se deseja aumentar a solubilidade de determinados compostos, pequenas quantidades de modificadores mais polares, tais como o metanol e o etanol, podem ser adicionados a fase móvel [7].

Na Figura 15.2 é apresentada uma representação esquemática de uma partícula de fase estacionária de sílica. 


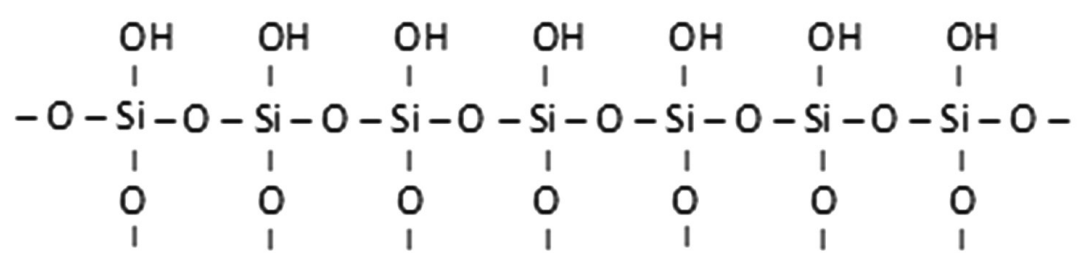

Figura 15.2. Estrutura da parte superficial de partícula de sílica utilizada como fase estacionária normal.

Além das fases estacionárias normais anteriormente citadas, modificações nos grupos hidroxilas da sílica permitem a introdução de outros grupos hidrofílicos amino, ciano, dióis e 2-etil piridina na superfície das partículas. Estes grupos têm características diferentes das hidroxilas isoladas e podem provocar interações mais específicas com os solutos, favorecendo suas separações quando presentes em misturas de compostos.

A cromatografia supercrítica pode ser conduzida de maneira isocrática, onde a composição e propriedades físico-químicas da fase móvel são mantidas constantes durante toda a separação ou em modo gradiente. Assim como na HPLC, o gradiente na SFC pode ser realizado através da mudança da composição de modificadores na fase móvel. Outra forma de gradiente que pode ser utilizada na SFC é o aumento de pressão durante a separação. Com este aumento, há um incremento na densidade do fluido supercrítico o que leva a um maior poder solvatante do mesmo. Com o aumento na solubilidade de alguns solutos no $\mathrm{CO}_{2}$ ocorre uma diminuição na interação dos mesmos com a fase estacionária facilitando o escoamento dos mesmos no interior da coluna. Outra propriedade físico-química que é alterada pelo aumento da pressão do sistema é a constante dielétrica do fluido supercrítico. No caso do dióxido de carbono, uma maior densidade do solvente leva a um aumento na intensidade do momento quadrupolar o que resulta em um solvente levemente mais polar. Este aumento da polaridade também pode interferir nas constantes de associação dos solutos com a fase estacionária, favorecendo a separação dos mesmos.

Através da escolha correta da fase estacionária normal e da fase móvel é possível realizar a separação de diversas classes de compostos por cromatografia. Assim, misturas de compostos orgânicos com grupos funcionais 
carboxílicos, amino, ésteres, éteres, aldeídos, cetonas, alcoóis, fenólicos, ácidos graxos, hidroxi ácidos, anilinas, sulfonamidas, fenil uréias, sulfonil uréias, triazinas, carbamatos, organo clorados e organo fosforados podem ser analisados utilizando estas colunas [6]. Para melhorar a eluição de compostos muito polares que tendem a ficar retidos na fase estacionário ou que formam picos de eluição muito distorcidos, pode ser necessária a utilização de aditivos além dos modificadores. Em geral, estes aditivos são bases como a dimetil etil amina ou ácidos como o trifluoroacético.

\subsubsection{Fases estacionárias reversas}

Nas fases estacionárias reversas, geralmente as hidroxilas presentes na superfície das partículas de sílica utilizadas como fases estacionárias normas são reagidas com silanos monoméricos para que ocorra a inversão da polaridade da superfície das mesmas. As fases reversas mais comumente utilizadas são a C8 e a C18, com 8 ou 18 átomos de carbono presentes na cauda hidrofóbica de hidrocarbonetos. Além destas, fases estacionárias contendo grupos fenil na superfície de partículas de sílica também podem ser utilizadas. A Figura 15.3 apresenta um esquema de fase estacionária de fase reversa do tipo C18.

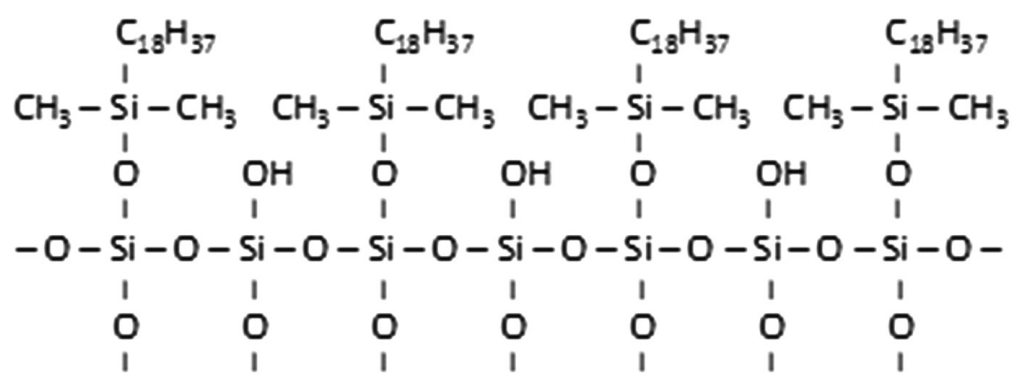

Figura 15.3. Estrutura da superfície de uma partícula utilizada como adsorvente para cromatografia em fase reversa.

$\mathrm{Na}$ cromatografia utilizando adsorventes em fase reversa, principalmente as interações do tipo van der Waals são responsáveis pelo retardo 
dos solutos no interior da coluna. Devido ao dióxido de carbono ser um solvente hidrofóbico, a amplitude de aplicação destes adsorventes é bem mais restrita do que das fases normais, sendo empregados na separação de hidrocarbonetos, aminas terciarias, éteres, ésteres, aldeídos, cetonas e ácidos graxos monofuncionais [6]. Em geral, dióxido de carbono puro ou com pequenas quantidades de metanol ou etanol são utilizados como fase móvel destas separações.

\subsubsection{Fases estacionárias de reconhecimento quiral}

A quantificação de isômeros óticos presentes em uma amostra é uma prática cada vez mais empregada, principalmente quando o soluto (ou analítos) de interesse for um fármaco. Há diversos relatos de diferentes atividades biológicas dos dois enantiômeros presentes na mistura racêmica, inclusive de reações adversas. Nas fases estacionárias de reconhecimento quiral, onde um isômero ótico adsorve mais intensamente que o outro, geralmente há diversos tipos de interações entre os solutos e os grupos seletores. As principais interações encontradas são ligações de hidrogênio, dipolo-dipolo, p-p e, diferentemente das outras fases estacionárias, complexos de inclusão e impedimentos estéricos, são responsáveis para a separação dos enantiômeros.

Em geral, matrizes de sílica são recobertas química ou fisicamente com ligantes ou seletores quirais. Os principais ligantes utilizados podem ser moléculas pequenas, conhecidas como ligantes de Pirkle, moléculas intermediárias como ciclodextrinas ou ainda macromoléculas como derivados de amilose e celulose, glicopeptídeos macrocíclicos ou ainda proteínas imobilizadas [8-10]. As principais modificações nas cadeias de amilose e de celulose são introdução de grupos acetato, benzoato, tris(4-metilbenzoatos) e diversos tipos de carbamatos para atuarem como grupos de reconhecimento quiral.

Diversas fases estacionárias de reconhecimento quiral estão disponíveis no mercado utilizando todos os tipos de grupos acima mencionados. O diâmetro da partícula, dos poros e a área superficial da sílica, bem 
como a distribuição espacial dos ligantes, têm efeito significativo sobre a eficiência de separação destas colunas.

A Figura 15.4 apresenta um esquema de uma fase estacionária de reconhecimento quiral de $\beta$-ciclodextrina, na qual $\mathrm{R}$ representa os grupos espaçadores utilizados para distanciar as ciclodextrinas da superfície da sílica e assim se orientarem de forma adequada para que ocorra a separação. Tridimensionalmente as ciclodextrinas tem forma toroidal de tronco de cones com grupos hidroxilas na parte externa e com cavidade (parte interna) hidrofóbica. O tamanho da cavidade hidrofóbica pode ser alterado pelo número de açúcares presentes na estrutura. Assim, a, b e g ciclodextrinas apresentam 6, 7 e 8 unidades de glicopiranoses em suas estruturas, respectivamente. Modificações químicas dos açúcares também podem resultar em diferentes interações com os enantiômeros.
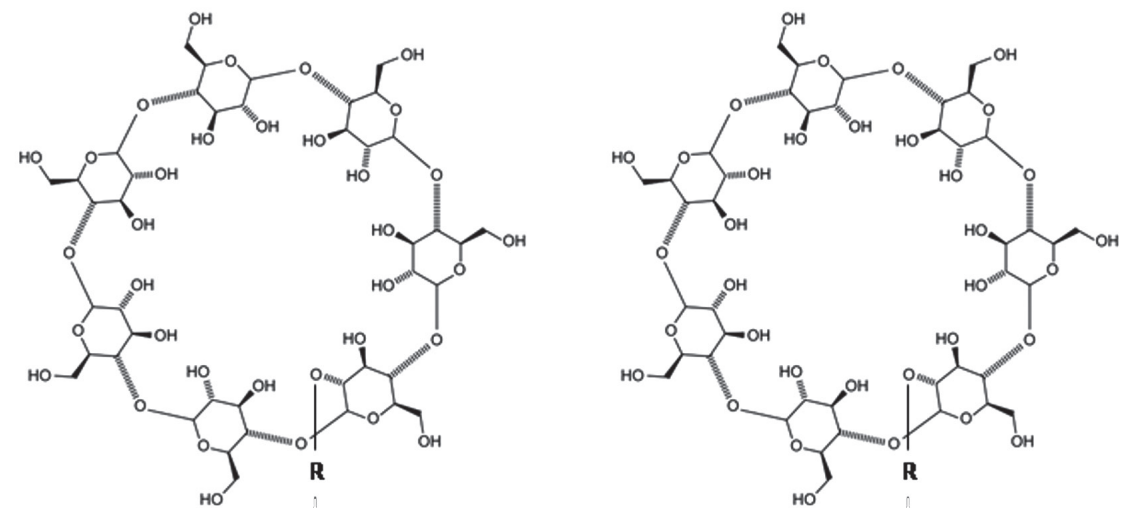

Figura 15.4. Representação esquemática de uma fase estacionária com grupos de reconhecimento quiral de $\beta$-ciclodextrina.

\subsubsection{Detectores utilizados na cromatografia supercrítica}

Há uma grande gama de detectores que podem ser utilizados para a detecção de compostos na cromatografia supercrítica uma vez que ela

é capaz de realizar a separação de solutos voláteis ou líquidos e podem ser realizadas em colunas abertas ou preenchidas. A detecção dos compostos separados pode ser feita diretamente na pressão de saída da 
coluna ou a baixa pressão. No último caso, o material que sai da coluna, passando ou não por um divisor de fluxo, escoa por um restritor de área, que pode ter diversas geometrias, onde ocorre a diminuição de pressão. Em geral, os detectores a alta pressão são adaptados da cromatografia líquida e apresentam alta densidade do fluido no momento da detecção enquanto que os que operam a baixas pressões são os adaptados da cromatografia gasosa [11].

Como as primeiras aplicações de SFC foram extensões naturais da cromatografia gasosa (CG), os detectores empregados nesta cromatografia foram os primeiros a serem testados. O detector de ionização de chama (FID) pôde ser diretamente conectado aos cromatógrafos supercríticos quando o $\mathrm{CO}_{2}$ foi utilizado com fase móvel, uma vez que ele não se ioniza na chama. No início das aplicações destes detectores eram observadas instabilidades nas linhas bases devido a formação de pequenos agregados de solutos com o dióxido de carbono [11]. Desta forma, algumas modificações nos equipamentos já amplamente utilizados na CG foram necessárias para utilização na cromatografia supercrítica [12]. As pontas dos injetores dos queimadores foram estreitadas para servirem como restritores para $\mathrm{O} \mathrm{CO}_{2}$. Estes restritores devem permitir uma descompressão rápida e constante do material que deixa a coluna de separação [11]. Além disto, o hidrogênio ou metano começou a ser misturado na entrada anteriormente utilizada para admissão de ar e este começou a ser inflado diretamente na câmara de combustão [12]. Mesmo com estas adaptações, os detectores do tipo FID apresentavam resultados satisfatórios para a análise do material que saia da coluna de separação. Apesar do sucesso relativo da adaptação do detector de ionização de chamas para a cromatografia supercrítica, os outros detectores utilizados na cromatografia gasosa não se mostraram efetivos para a cromatografia supercrítica devido a uma quantidade intensa de ruídos e flutuações na temperatura devido a expansão da fase móvel. Mais recentemente, devido a melhoria dos sistemas de controle de separação das correntes da saída das colunas de separação empacotadas e utilização de séries de restritores aquecidos para a descompressão da fase móvel permitiram o retorno dos detectores universais utilizados na cromatografia gasosa além da extensão 
de detectores a baixa pressão utilizados na cromatografia líquida. Assim, detectores tais como de ionização de chama (FID), de chama acústicos (AFD), de aerossóis carregados por efeito corona (CAD), de espalhamento de luz evaporativos (ELSD) [2] e de emissão atômica em plasma induzida por micro-ondas [13] são empregados na cromatografia supercrítica.

Além dos detectores a baixa pressão, o detector UV-Vis utilizado extensivamente em HPLC é o mais empregado na SFC, porém a altas pressões. O dióxido de carbono não apresenta absorção de luz significante na faixa do UV, e, portanto não dificulta a medida de solutos que apresentem absorção nesta faixa. A restrição encontrada nestas medidas é a necessidade de construção de células de medida que resistam às altas pressões empregadas sem grandes atenuações dos sinais [11]. Sistemas espectrofotométricos de matriz de diodo (UV/DAD) estão disponíveis comercialmente. No caso da separação de misturas racêmicas, detectores de dicroísmo circular (CD), também disponíveis comercialmente para utilização a altas pressões, podem ser utilizados para realização da detecção dos enantiômeros puros.

A detecção pela medida da absorção de luz na região do infravermelho (IR) pode ser realizada tanto a alta quanto a baixa pressão. As medidas sem a descompressão da fase móvel é, teoricamente, mais fácil, porém a absortividade do dióxido de carbono a altas pressões é relativamente alta, principalmente nas faixas de 3800 a $3500 \mathrm{~cm}^{-1}$ e de 2500 a $2200 \mathrm{~cm}^{-1}$ [11].

Finalmente, detectores baseados em espectrometria de massas também são empregados na cromatografia supercrítica. As dificultadas iniciais encontradas para sair de um sistema de alta pressão utilizado na coluna de separação para um sistema a vácuo de detecção parecem ter sido suplantadas sendo que há diversos sistemas comerciais de cromatografia supercrítica que tem a opção de detectores de espectrometria de massas.

\subsubsection{Parâmetros cromatográficos}

Alguns parâmetros cromatográficos são de vital importância na avaliação de um sistema de separação. A Figura $\mathbf{1 5 . 5}$ apresenta uma representação de picos detectados após uma coluna de cromatografia supercrítica. 


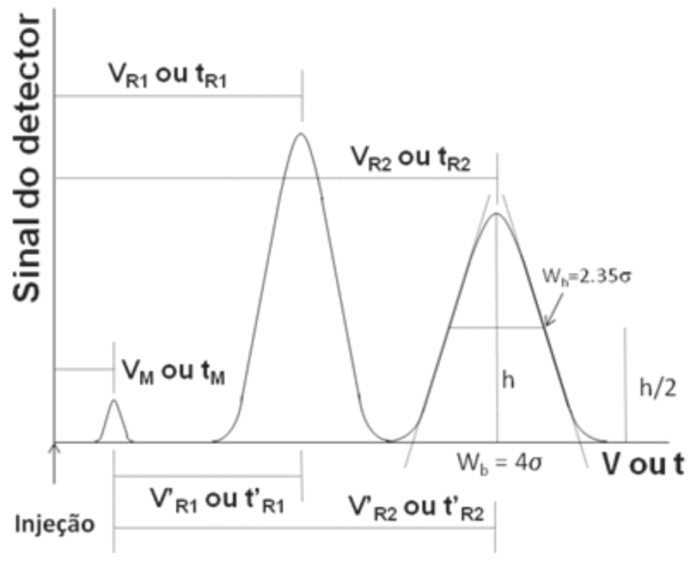

Figura 15.5. Representação esquemática de uma separação cromatográfica.

Na Figura 15.5 pode ser observada a variação da medida do sinal do detector presente após a coluna de separação como uma função do tempo ou volume de fase móvel que passa no sistema após a injeção da mistura de solutos no sistema. $V_{M}$ ou $t_{M}$ representam o volume ou tempo morto (hold-up) do sistema cromatográfico, ou seja, o tempo (ou volume) que um material que não tenha interação com a fase estacionária e com nenhuma para interna do sistema cromatográfico demora desde sua injeção até a passagem pelo detector. $\mathrm{V}_{\mathrm{R} 1}$ e $\mathrm{t}_{\mathrm{R} 1}$ representam o volume ou tempo de retenção do soluto com menor interação com a coluna cromatográfica enquanto que $V_{R 2}$ e $t_{R 2}$ de um composto maior interação com a fase estacionária. Estas variáveis podem ser corrigidas pelo tempo morto do sistema e, neste capítulo, são expressos com o sobrescrito '. Estes valores representam somente o efeito da interação da fase estacionária sobre o volume ou tempo de retenção dos solutos com maior ou menor interação no sistema. $\mathrm{w}_{\mathrm{h}}$ representa a largura do pico na metade de sua altura $(\mathrm{h} / 2)$ enquanto que $\mathbf{w}_{\mathrm{b}}$ representa a largura do pico em sua base. $\mathrm{s}$ representa o desvio padrão do pico considerando que o mesmo seja gaussiano. Além destes parâmetros dos picos dos solutos na saída da coluna, outros parâmetros são importantes de serem definidos.

O fator de retenção, $k$, representa a diferença entre os tempos de retenção do pico de um soluto com o tempo morto do sistema e dividido 
pelo tempo morto. Este fator representa a intensidade de interação do soluto com a fase estacionária. Este fator pode ser utilizado como uma primeira tentativa para a identificação de um soluto, que pode ter seu fator de retenção comparado com o obtido pela injeção de padrões do soluto puro. Assim, pela Figura 15.5 pode-se concluir que o soluto 2 tem fator de retenção maior que o soluto 1 . A expressão matemática do fator de retenção é então dada por:

$$
k_{1}=\frac{t_{R 1}-t_{M}}{t_{M}}
$$

O fator de separação, a, por sua vez, representa a relação entre os fatores de retenção de dois picos de solutos adjacentes e é dado por:

$$
\alpha=\frac{k_{2}}{k_{1}}=\frac{t_{R 2}-t_{M}}{t_{R 1}-t_{R 2}}
$$

Quanto mais longe o valor do fator de separação for do valor unitário, maior será a distância entre os valores máximos entre os picos adjacentes. Isto é um desejável para a separação do soluto mas não garante que os mesmos apresentem interpenetração dos picos devido a espessura de suas bases. Assim, um terceiro parâmetro é definido como resolução e é dado, para dois picos adjacentes, como

$$
R_{s}=\frac{t_{R 2}-t_{R 1}}{\left(w_{b 2}+w_{b 1}\right) / 2}=\frac{2\left(t_{R 2}-t_{R 1}\right)}{w_{b 2}+w_{b 1}}
$$

Quando a resolução é maior do que 1, temos que os picos adjacente não estão sobrepostos e, pode assim, ser analisados para a identificação do soluto e/ou para sua quantificação. Desta forma, as condições da cromatografia supercrítica tais como pressão, temperatura, quantidade e tipo de modificadores, quantidade e tipo de aditivos e tipo de fase estacionária utilizada devem ser otimizadas para que ocorra a resolução completa dos solutos de interesse. 
A eficiência de uma coluna de separação pode ser obtida pela determinação do número de estágios de equilíbrio que estão presentes em seu interior. Assim, quanto maior for o número de interações que ocorram na coluna maior será a resolução do sistema. O número de estágios de equilíbrio, também conhecido como número de pratos teóricos $(\mathrm{N})$, pode ser calculado pelas seguintes relações, se os picos puderem ser considerados como gaussianos:

$$
\begin{gathered}
N=\left(\frac{V_{R}}{\sigma}\right)^{2}=\left(\frac{t_{R}}{\sigma}\right)^{2} \\
N=16\left(\frac{V_{R}}{w_{b}}\right)^{2}=16\left(\frac{t_{R}}{w_{b}}\right)^{2} \\
N=5,545\left(\frac{V_{R}}{w_{h}}\right)^{2}=5,545\left(\frac{t_{R}}{w_{h}}\right)^{2}
\end{gathered}
$$

Assim, uma coluna com um valor de $\mathrm{N}$ maior será mais eficiente para a separação do soluto. Outra forma de verificar a eficiência de uma coluna cromatográfica é através da determinação da altura dos estágios de equilíbrio. Isto pode ser realizado através da divisão da altura da coluna pelo número de pratos teóricos, ou seja:

$$
H=\frac{L}{N}
$$

Uma coluna terá grande eficiência de separação quando a altura de um estágio de separação for muito pequeno. A altura do prato de separação pode ser alterada pelas limitações a transferência de massa e zonas de mistura que ocorrem na coluna cromatográfica. A equação de van Deemter é utilizada para a determinação da vazão ótima para um processo de separação e é dada por:

$$
H=A+\frac{B}{v}+C v
$$

Na equação 15.6 A representa a contribuição para a altura do prato de equilíbrio devido a dispersão do pico causada pelos múltiplos caminhos 
que um soluto pode ter durante sua passagem pela coluna cromatográfica, B representa a dispersão do pico devido a difusão do soluto presente na banda de separação e $\mathrm{C}$ a facilidade de transferência de massa de um soluto da fase estacionária para a fase móvel. Ainda nesta equação, v representa a velocidade linear (o fluxo de material na coluna), dado pela relação entre a vazão da fase móvel pela área da seção transversal da coluna. Desta forma, a velocidade linear da fase móvel deve ser tal que a altura do estágio teórico, $\mathrm{H}$, seja mínima. Como o segundo e terceiro termos do lado direito da equação 15.6 apresentam comportamentos distintos em relação a velocidade linear, a altura do prato teórico deve ter um valor mínimo para um determinado valor da velocidade linear. A Figura 15.6 apresenta um comportamento típico da equação de van Deemter.

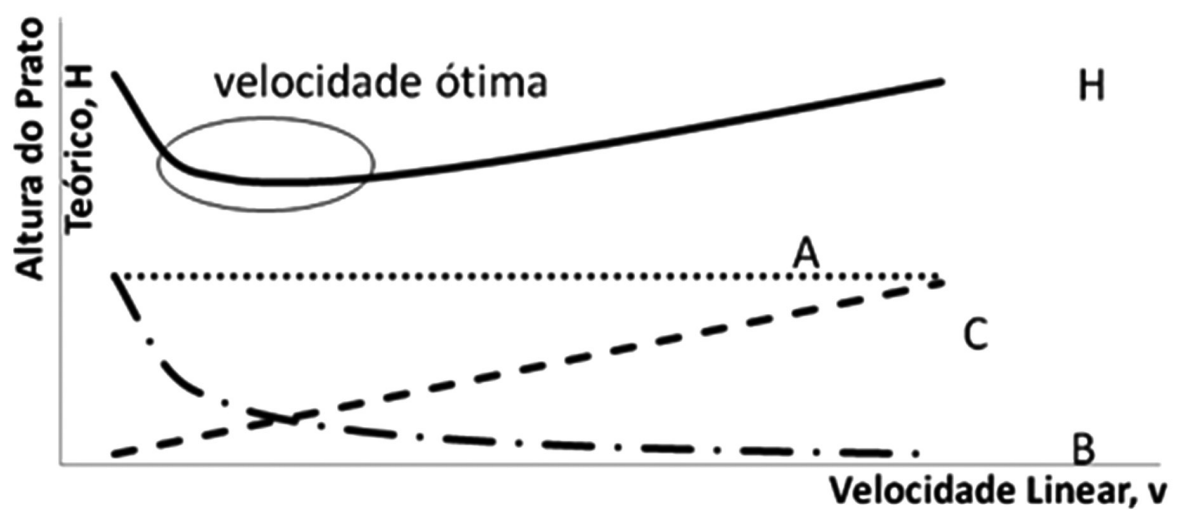

Figura 15.6. Representação da importância dos termos da equação de van Deemter sobre a altura dos pratos teóricos de uma coluna cromatográfica.

O gráfico de van Deemter para diversos tamanhos de partícula da fase estacionária utilizando cromatografia supercrítica foi apresentada por Gere et al. em 1982 [14]. Com a diminuição do tamanho das partículas há uma diminuição na altura do prato teórico e um deslocamento das velocidades ótimas para valores mais elevados de velocidade linear. Estes dois efeitos tem importância para a separação. Uma diminuição da altura do estágio de equilíbrio leva a uma maior resolução de picos adjacente utilizando uma mesma altura de coluna e o aumento da 
velocidade linear representa um aumento na produtividade do sistema. Assim, um número maior de amostras podem ser analisadas por unidade de tempo. De fato, o curva de van Deemter para partículas de $3 \mathrm{~mm}$ mostram que há uma diminuição da altura do prato teórico para velocidades lineares até cerca de $0,6 \mathrm{~cm} / \mathrm{s}$ ficando praticamente constante até velocidade lineares de $1,2 \mathrm{~cm} / \mathrm{s}$. Neste mesmo artigo é apresentada uma comparação dos gráficos de van Deemter para partículas utilizadas em HPLC e SFC. Para partículas com $10 \mathrm{~mm}$ de diâmetro o gráfico para HPLC apresenta maiores alturas de prato teórico e menor velocidade linear ótima do que o apresentado para o SFC com mesmo diâmetro de partícula. Quando a comparação é realizada para as partículas de 3 $\mathrm{mm}$, a altura dos pratos teóricos são praticamente iguais, porém a velocidade ótima para o HPLC é de cerca de $0,2 \mathrm{~cm} / \mathrm{s}$ enquanto que, para o SFC, velocidades da ordem de 0,6 a $1,2 \mathrm{~cm} / \mathrm{s}$ não alteram a altura do prato teórico de maneira significante. Recentemente Grand-Guillaume Perrenoud et al. [15] apresentaram uma comparação entre os gráficos de van Deemter para partículas de 3,5 e 1,7 $\mathrm{mm}$ de diâmetro utilizadas nas cromatografias líquida e supercrítica de ultra alta eficiência. Os resultados obtidos para as alturas dos pratos teóricos ótimos foram bem similares para ambos os sistemas e novamente a velocidade ótima foi maior para a SFC. Além do gráfico de van Deemter estes autores apresentaram as curvas de perda de carga na coluna para cada sistema. Os valores observados para o sistema de SFC foram bem inferiores aos observados para o HPLC o que realmente possibilita as maiores velocidades lineares e produtividade no sistema supercrítico.

\subsubsection{Aplicações de cromatografias supercríticas analíticas}

Existem diversos relatos na literatura da aplicação da cromatografia supercrítica em fase normal, em fase reversa e na separação de enantiômeros. Neste item, serão apresentados alguns sistemas estudados bem como as principais vantagens e desvantagens apresentadas pela cromatografia supercrítica. Devido às características físico-químicas do 
dióxido de carbono supercrítico, a modalidade de cromatografia menos frequente é a de fase reversa, apesar de alguns bons resultados obtidos.

Em relação ao tipo de coluna empregada, a partir da metade dos anos 90, grande parte dos sistemas utilizam colunas empacotadas, as quais terão maior enfoque neste item. Recentemente, somente o artigo de Thiébaut [16], focado na separação de compostos de petróleo, utilizou colunas abertas para realização de cromatografia supercrítica. A SFC apresentou melhores reultados na caracterização de hidrocarbonetos de alta massa molar do que a CG devido a maior solubilidade destes compostos no $\mathrm{CO}_{2}$ supercrítico. A cromatografia supercrítica foi hifenada a detectores do tipo espectroscopia de infravermelho com transformada de Fourier (FTIR), FID, UV e MS. O autor ainda sugere a utilização de cromatografias 2D em associação com CG ou do tipo SFC-SFC. Esta expansão da aplicabilidade de análise para compostos pouco voláteis é a principal vantagem da SFC se comparada a CG, apesar de apresentar menores números de pratos teóricos e maiores tempo de análise [17, 18].

O sucesso de utilização da SFC para separação de compostos mais polares utilizando fluidos supercríticos pode ser observada na extensa lista de artigos científicos com este tema presente na literatura. Comparado com a utilização da fase estacionária normal em sistemas de HPLC a SFC apresenta as vantagens de menores tempos de separação, maiores eficiências, reequilíbrio da coluna mais rápido, maior faixa de variáveis para otimização, menores tempos de otimização de um método, menores perdas de carga na coluna devido a menor viscosidade da fase móvel, menor custo do solvente, menores quantidade de solvente orgânico utilizado e de resíduos gerados, menores limites de detecção e maior reprodutividade $[2,6,17,19-22]$.

Diversos sistemas de análise foram desenvolvidos utilizando cromatografia supercrítica com fase estacionária normal. Heaton et al. [23] apresentaram uma comparação entre a análise de extratos supercríticos de folhas de Taxus baccata utilizando diversas colunas cromatográficas para a identificação e quantificação de taxanas usadas na semi-síntese do taxol. A análise forneceu melhores resultados quando uma coluna de nitrila foi utilizada. A eficiência de separação de felodipina, droga uti- 
lizada no tratamento da hipertensão, utilizando colunas de sílica tanto por HPLC quanto por SFC utilizando diversas concentrações de metanol como modificador foi testada através da comparação dos parâmetros cromatográficos obtidos em cada sistema [24]. Em todos os casos a eficiência de separação da SFC foi superior chegando a apresentar até 60\% mais pratos teóricos que a HPLC. Outro estudo comparativo entre a HPLC e a SFC foi realizado por Steuer et al. [25] para verificar as características de utilização de eluição dos solutos em utilizando gradiente de concentração de modificador (n-heptano). Os autores concluíram que a aplicação de gradientes de concentração do modificador foi mais efetiva para a SFC devido ao longo tempo de equilíbrio requerido pela HPLC. A SFC em coluna empacotada com sílica também foi testada para a separação de misturas petroquímicas com melhores separações observadas a maiores valores de pressão do sistema [26].

A análise de sistemas compostos por extratos vegetais [27-30], lubrificante para carro [31], princípios ativos de drogas [31-36] são encontrados na literatura. Apesar das fases estacionárias de sílica serem as mais importantes, colunas com diol e etil-piridina são frequentemente encontradas.

Colunas cromatográficas com fases estacionárias reversas também são empregadas na cromatografia supercrítica. A seletividade de fases estacionárias de C18 por hidrocarbonetos aromáticos policíclicos foi estudada por Williams et al. [37]. Os autores concluíram que a retenção dos solutos depende das variáveis cromatográficas de maneira similar à HPLC O reconhecimento aumenta com a diminuição da temperatura e com o aumento da quantidade de modificador (acetonitrila), tendo pouca influência da pressão do sistema. Os autores ainda observaram a inversão da ordem de eluição de solutos quando a mesma coluna era utilizada em HPLC e em SFC. West e Lesellier [7] realizaram um amplo estudo da interação de um grande número de solutos com 28 fases estacionárias distintas, muitas delas de fase reversa. Os autores apresentam cromatogramas de separação de misturas de cafeína, nicotinamida e fenil ureia com resolução completa para colunas contendo grupos fenil e com tempos de retenção menores dos que os obtidos com fase estacionária de sílica. Estes autores também discutem a dificuldade de classificação das fases 
estacionárias em termos de polaridade, como utilizada neste capítulo, devido à ampla variação da polaridade da fase móvel na cromatografia supercrítica, sugerindo que a classificação siga a da HPLC. Bamba et al. [20] utilizaram diversos tipos de coluna para realizar separação de lipídios utilizando cromatografia supercrítica e detector de espectrometria de massas, obtendo boas separações com colunas de fase reversa. Fases estacionárias contendo líquidos iônicos foram testadas para a separação de compostos como ibuprofeno, testosterona, fenoprofeno, acetaminofeno, metoprolol e naftaleno. Os resultados obtidos com esta fase estacionária foram superiores aos obtidos com colunas de C18.

A utilização de cromatografia supercrítica para análise de misturas racêmicas de 40 drogas comerciais foi estudada por Maftouh et al. [39]. Neste estudo foram testados os efeitos de diversas fases estacionárias quirais de polissacarídeos, composições da fase móvel e uso de aditivos na resolução dos enantiômeros. Somente na etapa de testes das fases estacionárias os autores conseguiram a separação das misturas racêmicas em cerca de $70 \%$ das drogas chegando a quase $100 \%$ de separação após uma etapa de otimização das condições de separação. A fase estacionária Chiralpak AD de sílica recoberta com tris(3,5-dimetilfenil carbamato) foi a que obteve maior sucesso na separação dos enantiômeros. Apesar do sucesso de separação e a facilidade para chegar aos resultados, os autores sugerem o desconhecimento da técnica cromatográfica, a complexidade do equipamento, o alto custo de capital e o desinteresse da maioria dos fornecedores dos equipamentos sejam os principais motivos para que a cromatografia supercrítica não seja a primeira opção para análise da pureza ótica de drogas.

Uma comparação da eficiência de separação de uma série de misturas racêmicas usando diversas fases estacionárias de reconhecimento quiral por HPLC e SFC foi realizada por Williams et al. [40]. Dependendo da fase estacionária e da mistura racêmica a resolução e o tempo de separação pode ser melhor por uma ou pela outra modalidade de cromatografia. Apesar disto, os autores concluíram que o equilíbrio da coluna e a otimização das condições de separação foram mais rápidas para a SFC do que para a HPLC. Trabalhos mais recentes [41-43] demonstraram que a 
separação de misturas racêmicas por SFC foi mais efetiva do que por HPLC e com tempos de separações menores.

\subsubsection{Equipamentos comerciais para cromatografia analítica}

Um dos motivos do retardo na aplicação da cromatografia supercrítica analítica em larga escala foi o desenvolvimento lento de equipamentos robustos e confiáveis [6]. Devido aos menores impactos ambientais relacionados com a menor utilização de solventes orgânicos, aos nichos de aplicações onde as cromatografias líquida e a gasosa não apresentam bons resultados e ao esforço de pesquisadores da área, principalmente do Dr. Terry Berger, da Berger Instruments, diversos sistemas comerciais foram desenvolvidos e estão disponíveis para comercialização. Dentre as peças críticas do sistema, válvulas controladoras de pressão automáticas e climatizadas e bombas para admissão do fluido supercrítico com vazões constantes, como as do tipo seringa, foram desenvolvidas e podem fazer parte destes sistemas cromatográficos.

Sistemas comerciais como o Analytical SFC - SF 2000 da Jasco, o Method Station SFC System e o Acquity UPSFC System da Waters, o 1260 Infinity Analytical SFC System da Agilent, o SF3 ${ }^{\mathrm{TM}}$ Supercritical Fluid Chromatography System da Gilson, entre outros, podem ser adquiridos com detectores do tipo UV-vis, UV/DAD, CD, ELSD, FID e MS.

\subsection{Cromatografia semi-preparativa}

Enquanto que na cromatografia analítica o objetivo é separar o máximo possível os solutos para permitir da melhor maneira a identificação ou quantificação dos mesmos, na cromatografia supercrítica semi-preparativa a separação é realizada para permitir a recuperação dos picos puros para posterior utilização. No caso analítico a otimização do sistema é realizada tentando diminuir o tempo da análise de forma que o número de análises por unidade de tempo seja maximizada. No sistema semi-preparativo a otimiza- 
ção é realizada para maximizar a quantidade de material puro recuperado por unidade de fase estacionária utilizada. Para tal, além da diminuição do tempo das separações, a quantidade de material injetado na coluna deve ser máxima de forma que ainda seja possível a resolução dos picos adjacentes. Na cromatografia semi-preparativa colunas com diâmetros até $50 \mathrm{~mm}$ de diâmetro e vazões intermediárias podem ser verificadas. Nestas condições, são possíveis produções de material puro da ordem de microgramas a gramas por dia. Um esquema de um cromatógrafo supercrítico em escala semi-preparativa pode ser observado na Figura 15.7.

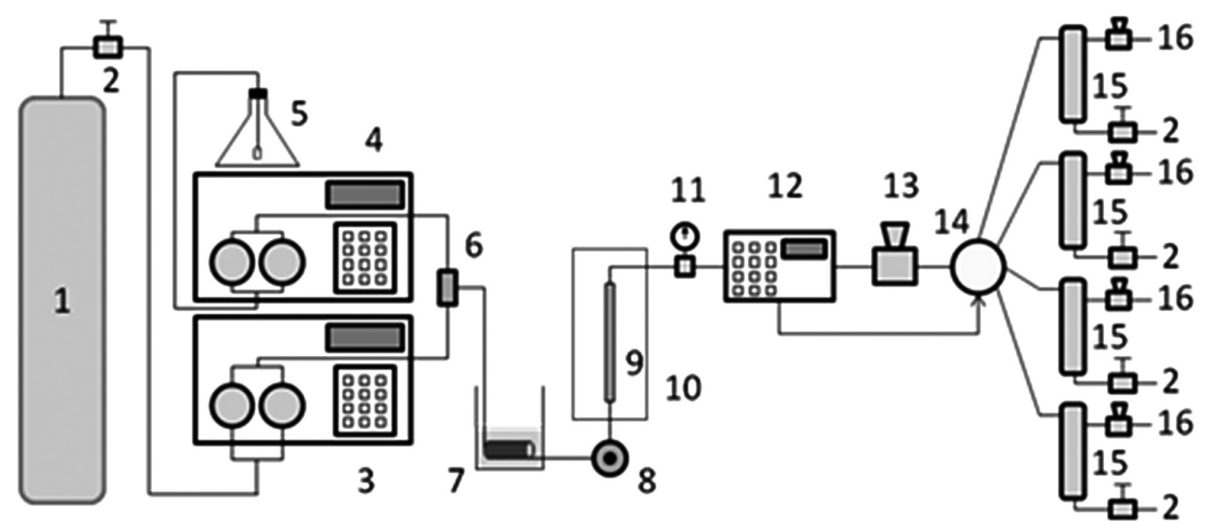

Figura 15.7. Representação esquemática de um cromatógrafo supercrítico em escala semi-preparativa. Os números de 1 a 13 representam os mesmos itens da Figura 15.6. (14) representa uma válvula seletora automática acionada pelo detector (12), (15) são frascos de coleta de frações e (16) geralmente são válvulas controladoras de pressão manuais.

Nesta escala de separação, o consumo de solventes orgânicos utilizados para a purificação por HPLC são muito grandes e, consequentemente, o custo de tratamento de efluentes também será elevado. Assim, a utilização da SFC passa ser mais atrativa uma vez que somente uma fração do solvente orgânico utilizado na HPLC é empregada.

O dióxido de carbono como um fluido supercrítico tem, em geral, um bom poder se solvatação dos compostos que estão sendo separados, mas no estado gasoso ele é não tem capacidade de solubilizar estes materiais. Assim, a descompressão do material que deixa a coluna cromatográfica 
leva a precipitação das frações que são retidas nos frascos de coleta. Esta fácil separação do soluto purificado do solvente é uma das principais vantagens da cromatografia supercrítica. A pressão ótima de separação pode ser um valor relativamente baixo, porém frequentemente com valores maiores do que o da pressão atmosférica, o que leva a frascos de separação que tem que ser resistente a valores intermediários de pressão. O projeto dos frascos de coleta é relativamente complexo uma vez que durante a descompressão pode ser formadas partículas pequenas que são facilmente arrastadas pelo $\mathrm{CO}_{2}$ gasoso. Um tipo de separador bastante utilizado é na forma de ciclones que diminuem a energia cinética das pequenas partículas através de seu atrito com a parte interna do separador.

\subsubsection{Otimização de processos de separação}

A otimização do processo de separação para a cromatografia supercrítica em escala semi-preparativa é relativamente fácil de ser realizado. Inicialmente, a seleção da fase estacionária e da fase móvel é realizada em um sistema de cromatografia em escala analítica, no qual a maior resolução de um ou vários solutos de interesse é maximizada. Após esta etapa inicial, a vazão da fase móvel no sistema semi-preparativo é otimizada e estudos de capacidade de injeção são realizados para identificar a quantidade máxima de material que pode ser injetado na coluna em escala semi-preparativa são realizados [44], conforme esquematizado na Figura 15.8.

Os ensaios podem ser realizados tanto pelo aumento da concentração da solução de injeção quanto pelo aumento de seu volume. Em ambos os casos pode-se perceber um alargamento do pico dos solutos separados. Quando o aumento da concentração é utilizado, além do alargamento do pico ocorre uma perda da simetria do mesmo (Figura 15.8) devido ao desvio da lei de Henry apresentada pela isoterma de adsorção (relação linear entre a concentração do soluto na fase móvel e estacionária). Diversas formas de desvio da lei de Henry podem ser observadas nos sistemas empregados em cromatografia supercrítica tais como apresentarem isotermas do tipo Langmuir ou com múltiplas camadas de adsorção 
[45]. Este estudo deve determinar o ponto no qual a resolução dos picos de interesse chegue a valores próximos do valor unitário e que maiores injeções iriam acarretar na produção de frações contaminadas com o material presente nos picos adjacentes.

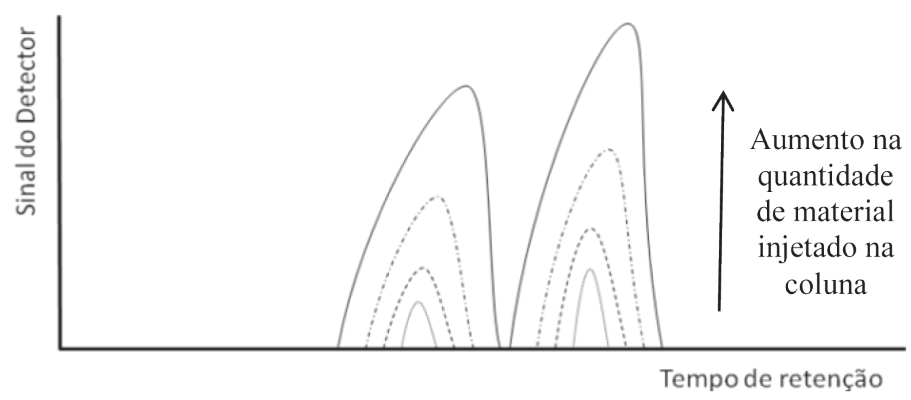

Figura 15.8. Representação esquemática de experimentos de determinação de capacidade de injeção em colunas de cromatografia supercrítica semi-preparativa.

Apesar do fluido supercrítico apresentar um bom poder de solvatação se comparado com o mesmo fluido em seu estado gasoso, em geral as baixas solubilidades observadas de diversos compostos não permitem uma grande variação da concentração da solução de injeção utilizada na SFC semi-preparativa.

Após esta etapa de otimização, o sistema é operado com injeções de solução a tempos pré-definidos de forma que não haja um grande tempo entre a saída de diversas injeções na saída da coluna, conforme ilustrada na Figura 15.9.

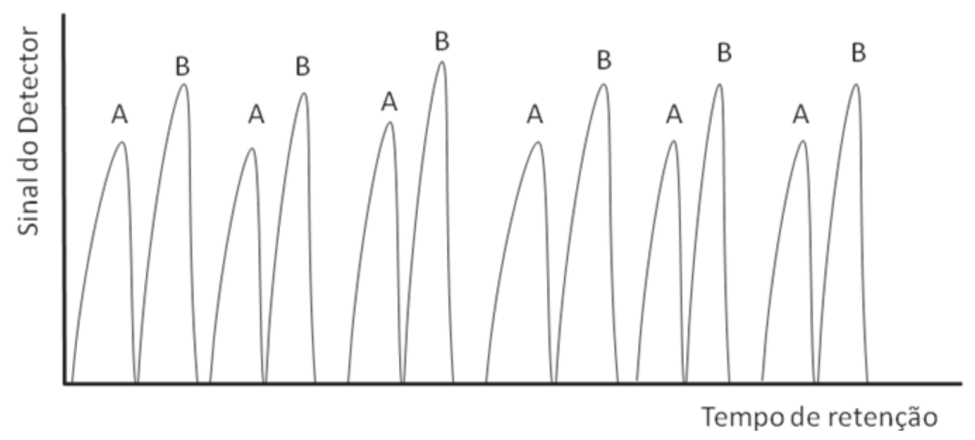

Figura 15.9. Esquema de operação de uma coluna cromatográfica supercrítica operando em escala semi-preparativa com múltiplas injeções. 
Na Figura 15.9, A pode representar o composto de interesse puro e B um segundo composto puro, como geralmente é o caso da purificação de misturas racêmicas, ou uma mistura de solutos não resolvidos, se estes não forem de interesse. Este esquema de múltiplas injeções pode ser realizado durante dias para a obtenção das quantidades requeridas do composto de interesse puro para posterior aplicação.

\subsubsection{Aplicações de cromatografia supercrítica semi-preparativa}

A cromatografia supercrítica em escala semi-preparativa é uma ferramenta importante no desenvolvimento de processos de produção de princípios ativos, nos estudos em pequenas escalas de aplicações de diversos compostos de interesse e no desenvolvimento de processos de purificação em escala preparativa. Um esquemas de purificação em escala semi-preparativa usando cromatografia supercrítica foi apresentada para o fracionamento de extrato de casca de limão obtido por prensagem a frio usando fase estacionária de sílica [46]. Os autores conseguiram três frações com composições bem distintas. Este método também foi utilizado para a purificação de uma série de compostos obtidos por química combinatorial com purezas maiores que 99\% nas frações coletadas [47]. Os autores conseguiram produtividades de 3 a 10 vezes maiores que em um sistema de HPLC com a mesma escala e com a mesma resolução. A separação de misturas racêmicas também foi realizada com sucesso em escala semi-preparativa para auxiliar o processo de desenvolvimento de drogas [48]. Apesar de haver outros artigos presentes na literatura utilizando o termo "cromatografia semi-preparativa", muitos autores acabam utilizando o termo de cromatografia preparativa mesmo para purificação de pequenas quantidades de material por SFC.

\subsubsection{Equipamentos comerciais para cromatografia semi-preparativa}

Apesar da definição de escala de processos cromatográficos utilizados neste capítulo seguir a classificação apresentada por Berger [6], os prin- 
cipais fabricantes de equipamentos comerciais de cromatógrafos acabam chamando de equipamentos preparativos o que aqui é definido como semi-preparativo. Como citado no item 15.3, um dos principais problemas encontrados nesta modalidade de cromatografia está associado com a dificuldade de recuperação completa do material purificado após a etapa de descompressão do fluido supercrítico com a consequente precipitação do soluto. Apesar de ocorrer a fácil separação do soluto do dióxido de carbono pela descompressão, parte dos modificadores e aditivos utilizados na separação também irão precipitar e estarão presentes nas frações de produtos purificados. Assim, etapas de remoção dos modificadores e aditivos deverão ocorrer para ter-se os produtos finais. Como a quantidade destes materias são bem menores do que as envolvidas na HPLC, os tempos e custos destes processos serão inferiores para a SFC.

Os equipamentos comerciais apresentam distintas formas e número de coletores de frações, o que possibilitam a obtenção de diversos picos cromatográficos puros em uma única separação. Os principais sistemas de separação em escala semi-preparativa encontrados comercialmente são o Semi-Prep SFC- SP-2086 e da Jasco, o SF3 ${ }^{\mathrm{TM}}$ Supercritical Fluid Chromatography System da Gilson, o SFC 80 Preparative Systems da Waters, o Prochrom® Supersep da Novasep, o SFC PICLab PREPTM 150 da PIC Solutions Inc., entre outros. O detector destas aplicações não podem ser destrutivos e geralmente os do tipo UV-vis, UV/DAD e CD são encontrados nestes equipamentos. Desta forma, produções da ordem de até gramas de composto puro podem ser obtidos nestes sistemas. Se o composto desejado for um principio ativo utilizado na preparação de fármacos para doenças mais raras, estes equipamentos podem ter capacidade industrial.

\subsection{Cromatografia preparativa}

Na cromatografia preparativa quantidades comerciais do composto de interesse puro são produzidas. Para tal, colunas com diâmetros de até $1,0 \mathrm{~m}$ e vazões de fase móvel maiores que $100 \mathrm{~mL} / \mathrm{min}$ são observadas. Estas colunas podem operar de forma descontínua, como no caso da cro- 
matrografia semi-preparativa, ou podem simular uma operação contínua, utilizando os leitos móveis simulados (SMB). Os SMB são utilizados na indústria de petróleo para a purificação de misturas de xilenos e serão discutidos no próximo subitem.

\subsubsection{Leito móvel simulado}

O leito móvel simulado é uma forma de cromatografia onde a introdução de alimentação da mistura de compostos e de dessorvente bem como a remoção de refinado (compostos com menores afinidades pela fase estacionária), extrato (materiais com maiores afinidades pela fase estacioária) e de dessorvente são realizados de forma contínua na série de colunas que compões estes sistemas. O desenvolvimento desta complexa unidade de separação ocorreu devido a impossibilidade da manutenção de admissão de fase estacionária em contracorrente com a fase móvel em uma única coluna, o que caracterizaria o leito móvel real. O movimento das fases móvel e estacionária ocorre pela mudança das posições das válvulas que controlam as corrente de entrada e de saída. No sentido apresentado na Figura 15.10, o movimento das fases ocorrem em contracorrente, aumentando a eficiência de separação. O SMB pode ser dividido em quatro zonas distintas. Na zona I ocorre a limpeza do adsorvente, na II ocorre o enriquecimento do soluto (ou solutos) que interage mais fortemente com a fase estacionária, que neste caso é o componente $\mathrm{B}$, na III ocorre o enriquecimento do composto (ou compostos) que tem menor interação com a fase estacionária (A) e na IV ocorre a limpeza do desorvente. O número de colunas presentes nas zonas do SMB podem variar. Alguns sistemas tem até 3 colunas em cada zona, o que favorece a sua estabilidade. Este tipo de equipamento tem como principais vantagens a recuperação quase total do $\mathrm{CO}_{2}$ e parcial dos modificadores (cerca de $76 \%$ [3]), permite a obtenção de frações com altas concentrações do material de interesse, operação contínua [44] e uma melhor utilização da fase estacionária [49]. A eficiência de separação pode ser obtida através da variação das vazões das correntes de extrato, refinado e dessorvente 
bem como do tempo de troca das correntes no sistema. Devido a presença de um grande quantidade de colunas em série, a perda de carga nestes sistemas deve ser elevada quando a fase móvel for líquida. Neste ponto a cromatografia supercrítica em leito móvel simulado permite a separação dos compostos com pequenas perdas de carga e com grande eficiência.

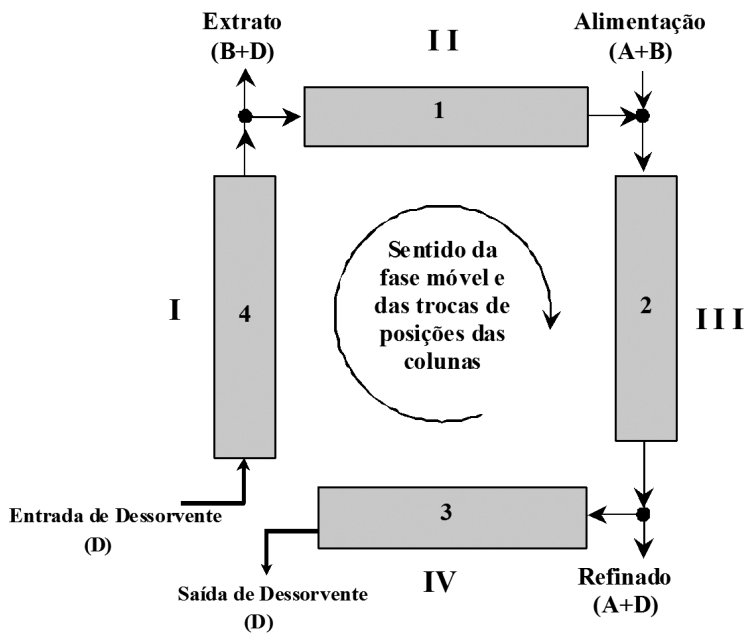

Figura 15.10. Representação esquemática de um sistemas de leito móvel simulado.

\subsubsection{Aplicações de cromatografia supercrítica preparativa}

Diversos relatos sobre o fracionamento de extratos de produtos naturais por cromatografia supercrítica em escala preparativa estão presentes na literatura. O enriquecimento de etil ester do ácido eicosapentaenóico (EPA) presente em misturas de etil ésteres obtidos a partir de óleo de peixe, com concentração inicial de $64 \%$ deste composto, foi estudado por Pettinello et al. [50] desde uma escala de bancada até em uma escala piloto, composta por duas colunas cromatográficas com 5 litros de volume e com vazões de $\mathrm{CO}_{2}$ de 20 a $25 \mathrm{~kg} / \mathrm{h}$. Neste trabalho foi utilizada fase estacionária de sílica e fase móvel contendo somente $\mathrm{CO}_{2}$. Os autores conseguiram uma fração contendo $93 \%$ de EPA com $24 \%$ de recuperação deste composto. Em relação ao aumento de escala, Rajandran [51] apresentou 
um esquema bem detalhado para a ampliação de escala em sistemas de cromatografia supercrítica em escala preparativa. Ramirez et al. [52, 53] realizaram o fracionamento de extratos de alecrim obtidos por extração supercrítica com o objetivo de obter frações com altas concentrações de compostos com atividade antioxidante. García-Risco et al.[54] utilizaram SFC em escala preparativa para enriquecer timol presente em extratos supercríticos de tomilho.

Um número considerável de aplicações de cromatografia supercrítica em escala preparativa está relacionada com a purificação de enantiômeros. Miller [55] apresentou uma extensa lista de aplicações de separações preparativas de misturas racêmicas de diversas drogas realizadas em laboratórios de empresas farmacêuticas por cromatografia supercrítica. Ren-Qi et al. [56] e de Klerck et al. [57] também apresentaram listas de misturas racêmicas que foram separadas com sucesso por cromatografia supercrítica. Estes autores reforçam a importância da utilização desta técnica de separação para o desenvolvimento de indústrias farmacêuticas "verdes".

A separação de compostos por cromatografia flash usando fluidos supercríticos foi estudada por Miller e Mahoney [58]. Nestes sistemas, uma certa quantidade da mistura de compostos é inserida na parte superior de uma coluna de adsorção e é utilizado um gás inerte para impulsionar o solvente na coluna. Ela permite a utilização e partículas menores que na coluna gravitacional e equipamentos mais simples e baratos que na HPLC. Os autores conseguiram boas separações para um número considerável de compostos com uma redução ainda maior do consumo de solvente se comparada a SFC convencional.

A posição da mistura entre o dióxido de carbono supercrítico e do modificador foi estudado por Miller e Sebastian [59]. No primeiro caso, foi utilizada a forma convencional da mistura, ou seja, antes da válvula de injeção. No segundo caso, o modificador puro passa pelo injetor e a mistura com o fluido supercrítico acontece entre a válvula de injeção e a coluna cromatográfica. Os autores concluíram que a forma de injeção pode ter grande impacto na forma do pico, dependendo da quantidade de modificador utilizada e do volume de amostra injetada. Em geral, a mistura do $\mathrm{CO}_{2}$ com o modificador após a válvula de injeção resultou em melhores resultados de separação. 
Os sistemas de leito móvel simulado com cromatografia supercrítica foram utilizados nas separações de enantiômeros de tetralol [60], Ibuprofeno [61], misturas racêmicas de bi-naftol e isômeros de fitol [62], misturas racêmicas de 1-fenil-1-propanol [63], cis e trans fitol [44], etil linoleato de etil oleato [64].

Apesar das vantagens técnicas que o leito móvel simulado tem sobre o sistemas de separação em batelada, Peper et al. [65] demonstraram que o custo de purificação de misturas racêmicas de ibuprofeno e de isômeros de tocoferol apresentaram maiores custos de purificação utilizando o SF-SMB do que o processo em batelada. Este resultado está relacionado com o alto impacto do investimento sobre o processo de separação, o que dilui a influência do adsorvente e do solvente sobre o custo final do produto. Já em relação a purificação por HPLC ou SFC, os autores concluem que são semelhantes e, portanto, devem ser verificados caso a caso para a seleção do melhor processo.

\subsubsection{Equipamentos comerciais para cromatografia supercrítica preparativa}

Boa parte dos produtores de equipamentos para cromatografia supercrítica semi-preparativa também oferecem equipamentos com maiores capacidades para a obtenção de compostos purificados com capacidade de dezenas de gramas até kilos por dia. Assim, o sistema Prep SFC-PR-2088 é capaz de produções de até dezenas de gramas por dia com vazões máximas de $120 \mathrm{~mL}$ de $\mathrm{CO}_{2} / \mathrm{min}$ e com até 8 frascos coletores, o sistemas SFC 350 é capaz de produzir até $100 \mathrm{~g}$ de material purificado por dia, com vazões máximas de $\mathrm{CO}_{2}$ de $300 \mathrm{~g} / \mathrm{min}$ e até seis frascos de coleta, o SFC PICLab PREPTM 1000 da PIC Solutions Inc., com produções de 100 a $1.000 \mathrm{~g}$ por dia, vazões de $\mathrm{CO}_{2}$ de até $1 \mathrm{~L} / \mathrm{min}$ e de 4 a 6 frascos de coleta e o Prochrom ${ }^{\circledR}$ Supersep 80-100 da Novasep com capacidade de produção de até dezenas de kilos, com vazões de até $3.000 \mathrm{~g} \mathrm{de} \mathrm{CO}_{2} / \mathrm{min}$ e com número variável de frascos de coleta. Como a vazões de dióxido de carbono nestes sistemas são consideráveis, estes possuem sistemas 
de reciclo de $\mathrm{CO}_{2}$ para diminuir o consumo do solvente, aumentar a viabilidade econômica do processo e aumentar o tempo de autonomia de utilização do equipamento. Provavelmente devido aos altos custos de instalação, não foram encontrados sistemas comerciais de cromatografia supercrítica utilizando leitos móveis simulados.

\subsection{Conclusão}

Desde o início de utilização até hoje, a cromatografia supercrítica passou por diversos estágios. Começou como uma alternativa para a cromatografia gasosa passando por uma época na qual se acreditava que ela iria substituir tanto a cromatografia gasosa como a líquida até chegar ao estágio atual onde procura o seu local entre as técnicas cromatográficas. Apesar de ter algumas vantagens técnicas sobre a cromatografia líquida como a maior eficiência de separação devido às menores limitações a transferência de massa, a maior facilidade de desenvolvimento de métodos e maiores produtividades tanto em escala analítica quanto em escala preparativa, aspectos econômicos ainda limitam a utilização desta técnica de uma forma mais ampla.

A utilização desta técnica de purificação é uma ferramenta útil no processo de desenvolvimento de princípios ativos de fármacos, principalmente os que necessitam purificações de isômeros óticos. A possibilidade de utilização de fases estacionárias de sílica, as quais são geralmente mais baratas, também representa uma vantagem da SFC.

A expansão do número de usuários de cromatografia supercrítica provavelmente irá impulsionar o desenvolvimento das técnicas e dos equipamentos que podem ser utilizados.

\subsection{Referências}

[1] E. Klesper, A. H. Corwin, D.A. Turner. J. Org. Phys. 1962, 27, 700.

[2] L. T. Taylor. Anal. Chem. 2010, 82, 4925.

[3] L. T. Taylor. J. Supercrit. Fluid 2009, 47, 566. 
[4] K.D. Bartle, A.A. Clifford, P. Myers, M.M. Robson, K. Sealy, D. Tong. ACS Symposium Series 2000, 748, 142.

[5] C. von Mühlen, F. M. Lanças. Quim. Nova 2004, 27, 747.

[6] T.A. Berger, In Drug Discovery, Supercritical Fluid Technology for Drug Product Development, P. York, U.B. Kompella, B.Y. Shekunov (Eds.), Marcel Dekker Inc., New York, Chapter 12, 460-497, 2004.

[7] C. West, E. Lesellier. J. Chromatogr. A. 2008, 1191, 21.

[8] J. Lindholm, T. Fornstedt. J. Chromatogr. A. 2005, 1095, 50.

[9] D.W. Armstrong, J. Zucowski. J. Chromatogr. A. 1994, 666, 445.

[10] W.H. Pirkle, J.M. Finn. J. Org. Chem. 1991, 558, 1.

[11] P.J. Schoenmakers, L.G.M. Uunk. Supercritical-Fluid Chromatography. In: Advances of Chromatography, vol. 30, J. D. Giddings, E. Crushka, P.R. Brown (Eds.), Marcel Dekker Inc., New York, Chapter 1, 1-80, 1989.

[12] M.G. Rawdon. Anal. Chem. 1984, 56, 831.

[13] F. Bertoncini, D. Thiébaut, M. Caude, M. Gagean, B. Carrazé, P. Beurdouche, X. Duteurtre. J. Chromatogr. A 2001, 910, 127.

[14] D. R. Gere, R. Board, D. McManigill. Anal. Chem. 1982, 54, 736.

[15] A. Grand-Guillaume Perrenoud, J. L. Veuthey, D. Guillarme. J. Chromatogr. A in press.

[16] D. Thiébaut. J. Chromatogr. A 2012, 1252, 177.

[17] C. F. Poole. J. Biochem. Biophys. 2000, 43, 3.

[18] R. P. Rodgers, A. M. McKenna. Anal. Chem. 2011, 83, 4665.

[19] T. A. Berger, W. H. Wilson. J. Biochem. Biophys. Methods 2000, 43, 77.

[20] T. Bamba, N. Shimonishi, A. Matsubara, K. Hirata, Y. Nakazawa, A. Kobayashi, E. Fukuzaki. J. Biosci. Bioeng. 2008, 105, 460.

[21] E. Lesellier. J. Chromatogr. A 2009,1216, 1881.

[22] A. J. Alexander, T. F. Hooker, F. P. Tomasella. J. Pharm. Biomed. Anal. 2012, $70,77$.

[23] D. Heaton, K. D. Bartle, C. M. Rayner, A. A. Clifford. J. High Resol. Chromatogr. 1993, $16,666$.

[24] J.T.B. Strode III, L.T. Taylor, A.L. Howard, D. Ip, M.A. Brooks. J. Pharmaceut. Biomed. $1994,12,1003$.

[25] W. Steuer, M. Schindler, F. Erni. J. Chromatogr. 1988, 454, 253.

[26] A. Venter, E. R. Rohwer, A. E. Laubscher. J. Chromatogr. A 1999, 847, 309.

[27] S. Buskov, H. Sorensen, S. Sorensen. J. High Resol. Chromatogr. 1999, 22, 339.

[28] S. Buskov, J. Hasselstrom, C. E. Olsen, H. Sorensen, J. C. Sorensen, S. Sorensen. J. Biochem. Biophys. Methods 2000, 43, 157.

[29] S. Buskov, C. E. Olsen, H. Sorensen, S. Sorensen. J. Biochem. Biophys. Methods 2000, 43, 175 .

[30] S. Li, T. Lambros, Z. Wang, R. Goodnow, C. T. Ho. J. Chromatogr. B 2007, 846, 291.

[31] G. Lavington, F. Bertoncini, D. Thiébaut, J. F. Beziau, B. Carrazé, P. Valette, X. Duteurtre. J. Chromatogr. A 2007,1161, 300 .

[32] Y. Hsieh, L. Favreau, J. Schwerdt, K. C. Cheng. . J. Pharmaceut. Biomed. 2006, 40, 799.

[33] H. Bui, T. Masquelin, T. Perun, T. Castle, J. Dage, M. S. Kuo. J. Chromatogr. A 2008, $1206,186$. 
[34] C. Brunelli, Y. Zhao, M. H. Brown, P. Sandra. J. Chromatogr. A 2008, 1185, 263.

[35] A. Cazenave-Gassiot, R. Boughtflower, J. Caldwell, R. Coxhead, L. Hitzel, S. Lane, P. Oakley, C. Holyoak, F. Pullen, G. J. Langley. J. Chromatogr. A 2008, 1189, 254.

[36] A. Cazenave-Gassiot, R. Boughtflower, J. Caldwell, L. Hitzel, C. Holyoak, S. Lane, P. Oakley, F. Pullend, S. Richardson, G. J. Langley. J. Chromatogr. A 2009, 1216, 6441.

[37] K.L. Williams, L.C. Sander, S.H. Page, S.A. Wise. J. High Resol. Chromatogr. 1995, 18, 477.

[38] F. M. Chou,W. T. Wang, G. T. Wei. J. Chromatogr. A 2009, 1216, 3594.

[39] M. Maftouh, C. Granier-Loyaux, E. Chavana, J. Mirini, A. Pradines, Y. V. Heyden, C. Picard. J. Chromatogr. A 2005, 1088, 67.

[40] K. L. Williams, L. C. Sander, S. A. Wise. J. Pharm. Biomed. Anal. 1997, 15, 1789.

[41] J. L. Bernal, L. Toribio, M. J. del Nozal, E. M. Nieto, M. I. Montequi. J. Biochem. Biophys. Methods 2002, 54, 245.

[42] L. Toribio, M. J. del Nozal, J. L. Bernal, C. Alonso, J. J. Jimenez. J. Chromatogr. A 2005, $1091,118$.

[43] C. Zhang, L. Jin, S. Zhou, Y. Zhang, S. Feng, Q. Zhou. Chirality 2011, 23, 215.

[44] A. Depta, T. Giese, M. Johannsen, G. Brunner. J. Chromatogr. A 1999, 865, 175.

[45] M. Lübbert, G. Brunner, M. Johannsen. J. Supercrit. Fluids 2007, 42, 180.

[46] Y. Yamauchi, M. Saito. J. Chromatogr. 1990, 505, 237.

[47] T. A. Berger, K. Fogleman, T. Staats, P. Bente, I. Crocket, W. Farrell, M. Osonubi. J. Biochem. Biophys. Methods 2000, 43, 87.

[48] Y. Zhao, G. Woo, S. Thomas, D. Semin, P. Sandra. J. Chromatogr. A 2003, 1003, 157.

[49] M. Mazzotti, G. Storti, M. Morbidelli. J. Chromatogr. A 1997, 786, 309.

[50] G. Pettinello, A. Bertucco, P. Pallado, A. Stassi. J. Supercrit. Fluids 2000, 19, 51.

[51] A. Rajendran. J. Chromatogr. A 2012, 1250, 227.

[52] P. Ramirez, M. R. García-Risco, S. Santoyo, F. J. Señoráns, E. Ibáñes, G. Reglero. J. Pharmaceut.Biomed. 2006, 41, 1606.

[53] P. Ramirez, S. Santoyo, M. R. García-Risco, F. J. Señoráns, E. Ibáñes, G. Reglero. J. Chromatogr. A 2007, 1143, 234.

[54] M. R. García-Risco, G. Vicente, G. Reglero, T. Fornari. J. Supercrit. Fluids 2011, 55, 949.

[55] L. Miller. J. Chromatogr. A 2012, 1250, 250.

[56] W. Ren-Qi, O. Teng-Teng, T Weihua, N. Siu-Choon. Trends Anal. Chem. 2012, 37, 83.

[57] K. de Klerck, D. Mangelings, Y. V. Heyden. J. Pharmaceut. Biomed. 2012, 69, 77.

[58] L. Miller, M. Mahoney. J. Chromatogr. A 2012, 1250, 264.

[59] L. Miller, I. Sebastian. J. Chromatogr. A 2012, 1250, 256.

[60] F. Denet, W. Hauck, R. M. Nicoud, O. Giovanni, M. Mazzotti, J. N. Jaubert, M. Morbidelli. Ind. Eng. Chem. Res. 2001, 40, 4603.

[61] S. Peper, M. Lubbert, M. Johannsen, G. Brunner. Sep. Sci. Technol. 2002, 37, 2545.

[62] M. Johannsen, S. Peper, G. Brunner. J. Biochem. Biophys. Methods 2002, 54, 85.

[63] A. Rajendran, S. Peper, M. Johannsen, M. Mazzoti, M. Morbidelli, G. Brunner. J. Chromatogr. A $2005,1092,55$.

[64] C. A. M. Cristancho, S. Peper, M. Johannsen. J. Supercrit. Fluids 2012, 66, 129.

[65] S. Peper, M. Johannsen, G. Brunner. J. Chromatogr. A 2007, 1176, 246. 